\title{
Robert Favreau, Poitiers, de Jean de Berry à Charles VII
}

Registres de délibérations du corps de ville $n^{\circ} 1,2$ et 3 (1412-1448)

\section{Michel Bouchaca}

\section{(2) OpenEdition}

Journals

Édition électronique

URL : http://journals.openedition.org/abpo/2886

DOI : $10.4000 / a b p o .2886$

ISBN : 978-2-7535-3977-8

ISSN : 2108-6443

Éditeur

Presses universitaires de Rennes

Édition imprimée

Date de publication : 15 décembre 2014

Pagination : 181-182

ISBN : 978-2-7535-3975-4

ISSN : 0399-0826

\section{Référence électronique}

Michel Bouchaca, «Robert Favreau, Poitiers, de Jean de Berry à Charles VII », Annales de Bretagne et des Pays de l'Ouest [En ligne], 121-4 | 2014, mis en ligne le 15 décembre 2014, consulté le 23 septembre 2020. URL : http://journals.openedition.org/abpo/2886 ; DOI : https://doi.org/10.4000/abpo.2886 
que l'image médiévale impose, il faut reconnaître l'intérêt de cette initiative dont le résultat est indéniable.

Enfin, Anne Nissen-Jaubert élargit le débat. Elle replace cette étude de l'Ouest dans les travaux actuels sur l'Occident et aborde la question de la continuité et/ ou rupture en posant le problème autrement et avec beaucoup de nuances. Les données chronologiques souvent larges ne permettent pas de fixer les différentes phases avec précision mais l'auteur relève le maintien des éléments structurants comme les chemins et les limites de parcelles, ce qui n'exclut pas une forte mobilité de l'habitat.

Le compte-rendu ne peut entrer dans les détails et montrer tout ce que le spécialiste des études régionales pourra trouver en termes de données et de comparaisons. Incontestablement, ces deux volumes sont une réussite. On hésite à émettre des regrets mais, puisque ce vaste corpus aborde la question de l'habitat, pourquoi ne pas entrer plus en débat avec les historiens qui se sont penchés sur la question? Quelques lignes de la conclusion nous laissent sur notre faim. En 2000, date d'achèvement de l'enquête, des travaux étaient déjà publiées, en particulier le volume de Flaran consacré à l'habitat dispersé. Les sites de l'étude appartiennent très majoritairement à cette catégorie d'habitats qui, bien que nommés écarts, terme un peu péjoratif, constituent l'élément majeur car le plus fréquent de la résidence des hommes, bien plus que le centre ecclésial qui ne regroupe souvent qu'un nombre limité d'habitants. Cette question essentielle ne peut progresser que par un débat nécessaire. Il faut le reconnaître, un tel travail rend ce dialogue possible en offrant un corpus de données et une réflexion de grande qualité, et souhaitable, car il devrait produire des fruits du plus grand intérêt.

Daniel PICHOT

FAVReau, Robert (dir.), Poitiers, de Jean de Berry à Charles VII. Registres de délibérations du corps de ville $n^{\circ} 1,2$ et 3 (1412-1448), Archives historiques du Poitou, t. LXVI, 2014, 464 p.

La collection des Archives historiques du Poitou vient de s'enrichir d'un $66^{\mathrm{e}}$ volume avec la publication des trois plus anciens registres de délibérations du corps de ville de Poitiers conservés pour les années 1412-1448. C'est le premier tome d'une série qui en comptera quatre à terme et qui couvrira l'édition intégrale des sept registres de délibérations municipales du Xve siècle aujourd'hui conservés à la médiathèque de Poitiers.

Une courte introduction (p. 7-14) présente ces sept registres, dont les trois qui font l'objet de la présente édition : le ${ }^{\circ} 1$, années 1412-1420; le $\mathrm{n}^{\circ} 2$, années 14211428 et le $n^{\circ} 3$, années 1436-1448. Une brève mise en perspective avec les autres publications de sources municipales pour les villes françaises montre combien le genre était tombé en déshérence de longue date.

Couvrant, malgré des lacunes, une grande partie de la première moitié du $\mathrm{XV}^{\mathrm{e}}$ siècle, ces trois registres permettent à l'historien de plonger au cœur des derniers soubresauts de la guerre de Cent Ans, à l'ombre de deux personnages marquants avec lesquels Poitiers a entretenu des relations plus ou moins étroites : Jean de Berry, flamboyant prince apanagiste détenteur du comté de Poitiers (mort en 1416, auquel son fils, également prénommé Jean, ne survécut qu'un an, le comté faisant alors retour à la Couronne), puis le dauphin Charles - «monsieur le Régent " comme se plaisent à l'appeler les sources poitevines - avant et après sa mue politique en roi 
de France en 1422. Au cours de ces années, le destin de la capitale provinciale qu'est Poitiers s'entremêle, toutes proportions gardées, avec celui du royaume de France par la présence dans ses murs ou dans ses environs de ces deux personnages et de leur entourage. En toute logique l'index des noms de personnes livre de nombreuses occurrences à chacune des rubriques qui les concernent (p. 446 et 452). Il en est de même pour " Poitiers " dans l'index des noms de lieux, qui offre la rubrique de loin la plus fournie et la plus diverse (p. 432-436).

Grâce à un travail méticuleux de transcription, d'édition critique et d'indexation, Robert Favreau livre un abondant et riche matériel documentaire qui illustre les nombreuses études qu'il a lui-même réalisées sur la capitale du Poitou. Les historiens en tireront profit pour poursuivre les recherches locales comme pour développer des comparaisons avec d'autres villes. Enfin le lecteur curieux et érudit aura tout loisir de parcourir l'ouvrage en quête de menus faits, voire d'anecdotes qui éclairent certains aspects de la vie quotidienne d'une capitale provinciale vue au prisme des délibérations de ses magistrats municipaux (fonctionnement institutionnel et affaires de la commune, clergé et institutions ecclésiastiques, dont l'université, topographie de la ville et activités économiques...). La vision que l'on en retire est certes partielle et parfois réductrice, mais on ne peut que remercier Robert Favreau d'en avoir grandement facilité l'accès. On attend donc avec impatience la publication des autres registres en faisant nôtre la formule de Georges Duby : "L'histoire continue ".

Michel BOCHACA

Dumont, Jonathan, FAGNART, Laure (dir.), Georges Ier d'Amboise, 1460-1510. Une figure plurielle de la Renaissance, Rennes, PUR, coll. « Histoire », 2013, 274 p.

Ce livre est le résultat d'un colloque international organisé à l'université de Liège en 2010 à l'occasion du 500 anniversaire de la mort du cardinal Georges I Ier d'Amboise, archevêque de Rouen, légat a latere et principal conseiller du roi de France, Louis XII. La rencontre, placée sous le signe de l'interdisciplinarité, réunit 17 spécialistes du Moyen Âge tardif et du début du XvI ${ }^{\mathrm{e}}$ siècle. Les contributions forment 262 pages organisées en trois parties autour de la personne de Georges d'Amboise illustrée tour à tour par ses " actions et images politiques ", son rôle de " bâtisseur, bibliophile et amateur d'art " et enfin de sa " mise au tombeau à la memoria ". Dans une rapide introduction, Jonathan Dumont et Laure Fagnart font le point sur la très riche historiographie du cardinal, qui va du panégyrique à la diatribe.

La première partie, " Georges d'Amboise, actions et images politiques ", revient sur le rôle politique du cardinal du temps du règne de Louis XII. Ancien compagnon du temps où celui-ci n'était que duc d'Orléans, le cardinal d'Amboise devient son principal conseiller à son avènement à la couronne de France. Incarnation du prélat d'État (dans la France du début du Xvi ${ }^{\mathrm{e}}$ siècle, un conseiller du roi sur trois est un ecclésiastique), le cardinal d'Amboise, fortement associé à Louis XII, est dépeint comme "le premier des grands ministres-favoris de la France moderne " (Cédric Michon, p. 26). Laurent Vissière s'efforce de discerner autant que possible la philosophie politique du cardinal d'Amboise. Celle-ci reposait sur une stratégie du glacis et des États-tampons qui préservait la Pax Gallica. Porter la guerre en Milanais, malgré bien des échecs, c'était conserver la paix en France (p. 56). Ainsi Georges d'Amboise s'appuya-t-il sur des grands feudataires pour tenir la Lombardie française à l'image de Jean-Jacques Trivulce, gouverneur par intérim du Milanais (Marino Vigano). À l'intérieur du royaume de France, le cardinal avait une vision " moderne " et réfor- 